\title{
Mean Platelet Volume and Long-Term Mortality in Patients Undergoing Percutaneous Coronary Intervention
}

\author{
Binita Shah, MD, MS ${ }^{a}$, Brandon Oberweis, MDa ${ }^{a}$, Lakshmi Tummala, MDa, Nicholas S. \\ Amoroso, $\mathbf{M D}^{\mathrm{a}}$, Iryna Lobach, $\mathbf{P h D}^{\mathrm{b}}$, Steven P. Sedlis, $\mathbf{M D}^{\mathrm{a}}$, Eugene Grossi, $\mathbf{M D}^{\mathrm{c}}$, and \\ Jeffrey S. Berger, MD, MS ${ }^{d}$ \\ aDepartment of Medicine, Division of Cardiology, New York University School of Medicine and \\ Veterans Affairs New York Harbor Health Care System, New York, NY \\ ${ }^{b}$ Department of Population Health, Division of Biostatistics, New York University School of \\ Medicine, New York, NY \\ 'Department of Cardiothoracic Surgery, New York University School of Medicine and Veterans \\ Affairs New York Harbor Health Care System, New York, NY \\ dDepartment of Medicine, Divisions of Cardiology and Hematology, New York University, School \\ of Medicine, New York, NY
}

\begin{abstract}
Increased platelet activity is associated with adverse cardiovascular events. Mean platelet volume (MPV) correlates with platelet activity but the relationship between MPV and long-term mortalityin patients undergoing percutaneous coronary intervention(PCI) is not well established. Furthermore, the role of change in MPV over time has not been previously evaluated. We evaluatedMPV at baseline, 30 days, 60 days, 90 days, 1 year, 2 years, and 3 years post-procedure in 1,512 patients who underwent PCI. The speed of change in MPV was estimated using slope of linear regression. Mortality was determined by query of social security death index. Over a median of 8.7 years, mortality was $49.3 \%$ post-PCI. There was no significant difference in mortality when stratified by MPV quartiles $\left(1^{\text {st }}\right.$ quartile $50.1 \%, 2^{\text {nd }}$ quartile $47.7 \%, 3^{\text {rd }}$ quartile $51.3 \%, 4^{\text {th }}$ quartile $\left.48.3 \%, \mathrm{p}=0.74\right)$. In patients with available data to determine a change in MPV over time post-PCI $(\mathrm{n}=839)$, mortality was $49.1 \%$ and significantly higher in patients with an increase $(52.9 \%)$ compared to those with a decrease (44.2\%) or no change (49.1\%) in MPV over time ( $\mathrm{p}<0.0001)$. In conclusion, there was no association between baseline MPV and long-term mortality in patients undergoing PCI. However, there was increased mortality when MPV increasedover time post-PCI. Monitoring MPV after coronary revascularization may play a role in risk stratification.
\end{abstract}

\section{Keywords}

Mean platelet volume; percutaneous coronary intervention; long-term mortality

(C) 2012 Excerpta Medica, Inc. All rights reserved.

Corresponding author: Jeffrey S. Berger, MD, MS, FAHA, New York University School of Medicine, 530 First Avenue, Skirball 9R, New York, NY 10016, Tel. 212-263-4004, Fax. 212-263-3988, jeffrey.berger@ nyumc.org.

Publisher's Disclaimer: This is a PDF file of an unedited manuscript that has been accepted for publication. As a service to our customers we are providing this early version of the manuscript. The manuscript will undergo copyediting, typesetting, and review of the resulting proof before it is published in its final citable form. Please note that during the production process errors may be discovered which could affect the content, and all legal disclaimers that apply to the journal pertain. 
Platelets play a pivotal role in the development of atherosclerotic lesions, plaque destabilization, and atherothrombosis (1). Antiplatelet therapy reduces both proceduralrelated complications, as well as subsequent ischemic cardiovascular events, after coronary revascularization (2-3). However, despite targeted therapy, up to a quarter of patients after percutaneous coronary intervention (PCI) demonstrate high platelet activity and a higher rate of major adverse cardiovascular events compared to patients without high platelet activity (4-5). Methods of testing platelet activity can be time consuming, expensive and technically difficult (6). Mean Platelet Volume (MPV), a marker of platelet size and activity, is a predictor of cardiovascular risk (7) and quantified on automated hemograms routinely measured prior to coronary revascularization. In the setting of PCI, high pre-procedural MPV is associated with increased mortality in patients with ST-segment elevation myocardial infarction (8) and increased rate of restenosis after coronary angioplasty (9). In this study, we aim to determine if pre-procedural MPV or the change in MPV over time is a predictor of long-term mortality in unselected patients undergoing PCI.

\section{Methods}

The present study is a retrospective analysis of patients referred from 8 facilities in Pennsylvania, New Jersey and New York who underwent PCI ( $n=1,625$ between January 1993 and October 2005) at the Manhattan Campus of the Veterans Affairs New York Harbor Healthcare System. Baseline MPV wasmeasured within two days of procedure, as well as at 30 days, 60 days, 90 days, 1 year, 2 years, and 3 years post-PCI where available. Patients with missing baseline MPV data $(n=86)$, baseline platelet count of $<100,000(n=15)$ or $>500,000(n=7)$, or unknown survival status post-PCI $(n=5)$ were excluded, leaving data on $1,512(93 \%)$ patients for analysis. Of this cohort, $44.5 \%(n=673)$ had insufficient data to determine if MPV changed over time post-PCI. Patients with sufficient data (at least 3 postPCI MPV values) to determine the direction of change in MPV over time post-PCI ( $\mathrm{n}=839$ ) were divided into 3 groups: increasing MPV $(n=157)$, decreasing MPV $(n=120)$, and no change in MPV over time ( $n=562)$.

Baseline characteristics and laboratory data were obtained from the cardiac catheterization laboratory database and from chart review of the Department of Veterans Affairs computerized patient records. Patients were classified as having diabetes mellitus if they had ever been treated with insulin or oral hypoglycemic agents, had a fasting glucose levels were $>126 \mathrm{mg} / \mathrm{dl}$ on 2 separate occasions, or had a random glucose value of $>200 \mathrm{mg} / \mathrm{dl}$ had been documented on $\geq 1$ occasion before the current admission. All other co-morbidities shown as baseline characteristics were ascertained by chart review of physician documentation of patient's medical history. The primary endpoint, defined as all-cause mortality after PCI was determined by query of both the Social Security Death Benefit Index and Veterans Affairs computerized patient records.

Patients were grouped according to baseline MPV quartile $\left(1^{\text {st }}\right.$ quartile, MPV $<8.2 \mathrm{fL} ; 2^{\text {nd }}$ quartile, MPV 8.2-8.8 fL; $3^{\text {rd }}$ quartile, MPV 8.8-9.4 fL; $4^{\text {th }}$ quartile, MPV >9.4 fL). Differences in baseline characteristics were evaluated by Chi-Square test for categorical variables. Normality was examined using histograms, quantile-quantile plots and ShapiroWilk test. Normally and non-normally distributed continuous variables were analyzed by one-way analysis of varianceand Kruskal Wallis test, respectively. Long-term mortality stratified by MPV quartile was compared using Chi-square test.

To examine trend in post-PCI MPV over time, speed of change in MPV was estimated using slope of a linear mixed effects regression model (10). The analysis was performed on logscale to ensure that corresponding residuals were Gaussian. An increase/decrease in MPV was inferred based on analysis of slopes and a 0.05 p-value cut-off. Because estimates of 
mortalities corresponding to increasing, decreasing, and no change in MPV did not change when the p-value cut-off was relaxed to 0.1 , estimates of slope that passed the 0.1 significance were defined to be statistically significant. To examine sensitivity of the results of this trend analysis, we examined a more stringent definition of the cut-off by requiring at least 4 post-PCI MPV values. Long-term mortality was compared between increasing MPV group versus decreasing or no change in MPV group using binomial test of proportions. Survivor distribution is presented using Kaplan-Meier curves and compared using one-sided log-rank test.

To explore the relationship between increasing MPV versus non-increasing MPV (decreasing or no change in MPV) and long-term mortality, logistic regression was used with mortality as the dichotomous outcome and increasing MPV as the main predictor. We built models hierarchically to include clinical factors that affect mortality and/or MPV. First we added demographic variables of age, followed by race (sex was not included as the study population was $99 \%$ male), into the logistic regression model. This was followed by sequentially adding diabetes and peripheral vascular disease, to the logistic regression model, and, lastly, creatinine and tobacco use. Since baseline MPV was not different between the increasing, decreasing, and no change groups, and baseline MPV was not a predictor of mortality in this cohort, it was not included in the model.

Statistical analysis was conducted using the Statistical Package for Social Sciences software, version 19.0 (SPSS, Chicago, Illinois) and R program for Scientific Computing (www.rproject.org). The protocol was approved by the VA human studies committee.

\section{Results}

Baseline characteristics by MPV quartiles are shown in Table 1. Mortality on follow-up after PCI was $49.3 \%$ (median follow-up 8.7 years). There was no significant difference in long-term mortality observed when stratified by baseline MPV quartiles $\left(1^{\text {st }} 50.1 \%, 2^{\text {nd }}\right.$ $\left.47.7 \%, 3^{\text {rd }} 51.3 \%, 4^{\text {th }} 48.3 \%, p=0.744\right)$. Similarly, 1 -year mortality $\left(1^{\text {st }} 8.1 \%, 2^{\text {nd }} 5.7 \%, 3^{\text {rd }}\right.$ $\left.7.0 \%, 4^{\text {th }} 7.2 \%, \mathrm{p}=0.625\right)$ and 3 -year mortality $\left(1^{\text {st }} 16.5 \%, 2^{\text {nd }} 14.2 \%, 3^{\text {rd }} 16.3 \%, 4^{\text {th }} 15.7 \%\right.$, $\mathrm{p}=0.821$ ) did not differ across baseline MPV quartiles.

Data was available to determine the direction of change in MPV over time post-PCI in 839 (55.5\%) patients. When comparing the baseline characteristics between patients with $(\mathrm{n}=839)$ and without $(\mathrm{n}=673)$ available data to determine changes in MPV over time postPCI, the patients with available data were older ( 67 vs 65 years, $\mathrm{p}=0.003$ ), with higher prevalence of diabetes mellitus ( $43 \%$ vs $37 \%, \mathrm{p}=0.02)$ and hypertension ( $79 \%$ vs $74 \%$, $\mathrm{p}=0.017)$. Patients with available data also had lower prevalence of tobacco use ( $26 \%$ vs $32 \%, \mathrm{p}=0.021)$ and lower platelet levels $\left(205 \mathrm{vs} 217 \times 10^{9} / \mathrm{L}, \mathrm{p}=0.014\right)$ compared to patients without available data. Other baseline characteristics and mortality on follow-up post-PCI $(49.1 \%$ vs $49.5 \%, \mathrm{p}=0.918)$ were similar in patients with compared to without available data.

Baseline characteristics of patients with available data to determine a change in MPV over time post-PCI are shown in Table 2 (19\% had increasing MPV, 14\% had decreasing MPV, and $67 \%$ had no change in MPV). Mortality on follow-up was significantly higher in patients with an increase in MPV over time following PCI (increase in MPV 52.9\%, decrease in MPV 44.2\%, no change in MPV 49.1\%; $<<0.0001$ between patients with an increase vs no increase in MPV). When evaluated over time, mortality remained significantly higher in patients with increasing compared with non-increasing (decreasing or no observed change) in MPV (Figure 1). The average annual increase in MPV was $1.02 \mathrm{fL}$ (standard deviation 0.12). 
Mortality was higher in patients with increasing MPV over time following PCI when adjusted for age and race. While significance was no longer present when adjusted further for diabetes, peripheral vascular disease, creatinine and smoking status, the point estimate remained comparable. (Table 3a)

When a more stringent definition of change in MPV was applied, there were 111 (7.3\%) patients with sufficient data available to determine the direction of change in MPV over time post-PCI. In this group, an increase in MPV over time $(n=69)$ was associated with a nearly 3 -fold higher risk of mortality compared to patients with non-increasing change in MPV over time ( $\mathrm{n}=42$ ) following PCI (unadjusted OR 2.8 (95\% CI 1.31-6.43), $\mathrm{p}=0.009$; adjusted for age, race, diabetes and peripheral vascular disease OR 2.61 [1.13-6.22], $\mathrm{p}=0.026$ ). (Table $3 b)$

\section{Discussion}

In an unselected patient population from the Manhattan Campus of the Veterans Affairs New York Harbor Healthcare System undergoing PCI, pre-procedural MPV did not correlate with long-term mortality risk, whereas increases in MPV over time were associated with increased long-term mortality. This is the first study to evaluate the association between both baseline MPV, as well as changes in MPV over time, and long-term mortality in patients with coronary artery disease.

While there are substantial data to suggest an association between MPV and cardiovascular events (7), there are little data in patients following coronary revascularization. Only one other study evaluated the relationship of pre-procedural MPV on long-term outcomes in unselected patients undergoing PCI (11). In this study of 1,432 patients undergoing PCI, pre-procedural MPV was associated with mortality or myocardial infarction at 1 year (11). We did not find this association in our study which may reflect a difference in patient population or a lack of power. Alternatively, baseline MPV may not be a good predictor of procedural complications with adverse prognostic effects. For example, during PCI, balloon inflations further aggravate thrombotic complications as a result of tissue factor and collagen release at the site of vessel wall injury, which results in sustained platelet activation (12). Baseline measurement of MPV would not be expected to predict such procedure related platelet activation.

The association between MPV and long-term mortality in the setting of PCI remains uncertain. The current study is a retrospective analysis of a large cohort from a tertiary carecenter with a similar sample size to the previous study (11), but our data do not show an association between a single pre-procedural MPV value and mortality on a much longer follow-up. This remains true when mortality was evaluated at 1 and 3 years. We do, however, demonstrate an association between an increase in MPV over time (presumably reflecting greater platelet activation) with long-term mortality, even after adjustment for age and race. Although there is some attenuation after further multivariate adjustment, the point estimate is roughly the same and, thus, this is likely due to lack of power. When more stringent criteria were used to determine the direction of change of MPV post-PCI, we demonstrated a stronger association between increase in MPV over time and long-term mortality even after multivariate adjustment. Our data suggest that serial assessments of MPV should be considered in evaluating prognosis.

There are several limitations. This is a retrospective analysis and only an association can be inferred from the data presented. Multiple factors affect MPV measurement, including method of collection, time from collection to analysis, and method of analysis, which is not captured in this study (13-15). However, other factors that correlate with MPV, such as 
diabetes mellitus, peripheral artery disease, and body mass index are accounted for here (1617). Although a detailed history of anti-platelet use is not recorded, aspirin use was captured and has not been shown to correlate with MPV (18). Details related to cause of mortality or other relevant endpoints, such as myocardial infarction, was not available. Finally, the population studied consisted mostly of white men and the same conclusions may not be applicable to other groups.

This is the first study to evaluate a change in MPV over time. As such, additional studies are warranted to test if the findings in this study are generalizable to different cohorts. Future studies aimed at targeting MPV or using change in MPV over time to stratify therapies are also needed.

\section{Acknowledgments}

Dr. Shah was partially funded by an NIH/NHLBI grant (T32HL098129). Dr Berger was partially funded by an American Heart Association Fellow to Faculty Award (0775074N) and a Doris Duke Clinical Scientist Award.

\section{References}

1. Davi G, Patrono C. Platelet activation and atherothrombosis. N Engl J Med. 2007; 357:2482-2494. [PubMed: 18077812]

2. Mehta SR, Yusuf S, Peters RJ, Bertrand ME, Lewis BS, Natarajan MK, Malmberg K, Rupprecht H, Zhao F, Chrolavicius S, Copland I, Fox KA. Clopidogrel in Unstable angina to prevent Recurrent Events trial (CURE) Investigators. Effects of pretreatment with clopidogrel and aspirin followed by long-term therapy in patients undergoing percutaneous coronary intervention: the PCI-CURE study. Lancet. 2001; 358:527-533. [PubMed: 11520521]

3. Steinhubl SR, Berger PB, Mann JT III, Fry ET, DeLago A, Wilmer C, Topol EJ. CREDO Investigators. Early and sustained dual oral antiplatelet therapy following percutaneous coronary intervention: a randomized controlled trial. JAMA. 2002; 288:2411-2420. [PubMed: 12435254]

4. Eikelboom JW, Hirsh J, Weitz JI, Johnston M, Yi Q, Yusuf S. Aspirin-resistant thromboxane biosynthesis and the risk of myocardial infarction, stroke, or cardiovascular death in patients at high risk for cardiovascular events. Circulation. 2002; 105:1650-1655. [PubMed: 11940542]

5. Bonello L, Pansieri M, Mancini J, Bonello R, Maillard L, Barnay P, Rossi P, Ait-Mokhtar O, Jouve B, Collet F, Peyre JP, Wittenberg O, de Labriolle A, Camilleri E, Cheneau E, Cabassome E, DignatGeorge F, Camoin-Jau L, Paganelli F. High on-treatment platelet reactivity after prasugrel loading dose and cardiovascular events after percutaneous coronary intervention in acute coronary syndromes. J Am Coll Cardiol. 2011; 58:467-473. [PubMed: 21777742]

6. Michelson AD. Methods for the measurement of platelet function. Am J Cardiol. 2009; 103(Suppl): 20A-26A.

7. Chu SG, Becker RC, Berger PB, Bhatt DL, Eikelboom JW, Konkle B, Mohler ER, Reilly MP, Berger JS. Mean platelet volume as a predictor of cardiovascular risk: a systematic review and meta-analysis. J Thromb Haemost. 2010; 8:148-156. [PubMed: 19691485]

8. Huczek Z, Kochman J, Filipiak KJ, Horszczaruk GJ, Grabowski M, Piatkowski R, Wilczynska J, Zielinski A, Meier B, Opolski G. Mean platelet volume on admission predicts impaired reperfusion and long-term mortality in acute myocardial infarction treated with primary percutaneous coronary intervention. J Am Coll Cardiol. 2005; 46:284-290. [PubMed: 16022956]

9. Yang A, Pizzulli L, Luderitz B. Mean platelet volume as marker of restenosis after percutaneous transluminal coronary angioplasty in patients with stable and unstable angina pectoris. Thromb Res. 2006; 117:371-377. [PubMed: 15935453]

10. Fitzmaurice, GM.; Laird, NM.; Ware, JH. Applied Longitudinal Analysis. New Jersey: WileyInterscience; 2004.

11. Goncalves SC, Labinaz M, Le May M, Glover C, Froeschl M, Marquis JF, O’Brien E, Shukla D, Ruchin P, Sookur D, Ha A, So D. Usefulness of Mean Platelet Volume as a Biomarker for LongTerm Outcomes after Percutaneous Coronary Intervention. Am J Cardiology. 2011; 107:204-209. 
12. Orford JL, Selwyn AP, Ganz P, Popma JJ, Rogers C. The comparative pathobiology of atherosclerosis and restenosis. Am J Cardiol. 2000; 86(suppl):6H-11H.

13. Park Y, Schoene N, Harris W. Mean platelet volume as an indicator of platelet activation: methodological issues. Platelets. 2002; 13:301-306. [PubMed: 12189016]

14. Bath PM. The routine measurement of platelet size using sodium citrate alone as the anticoagulant. Thromb Haemost. 1993; 70:687-690. [PubMed: 8115997]

15. Trowbridge EA, Reardon DM, Hutchinson D, Pickering C. The routine measurement of platelet volume: a comparison of light-scattering and aperture-impedance technologies. Clin Phys Physiol Meas. 1985; 6:221-238. [PubMed: 3930129]

16. Shah B, Sha D, Xie D, Mohler ER 3rd, Berger JS. The relationship between diabetes mellitus, metabolic syndrome and platelet activity as measured by mean platelet volume, the National Health and Nutrition Examination Survey, 1999-2004. Diabetes Care. 2012; 35:1074-1078. [PubMed: 22410814]

17. Berger JS, Eraso LH, Xie D, Sha D, Mohler ER 3rd. Mean platelet volume and prevalence of peripheral artery disease, the National Health and Nutrition Examination Survey, 1999-2004. Atherosclerosis. 2010; 213:586-91. [PubMed: 20940069]

18. Colkesen Y, Coskun I, Muderrisoglu H. The effect of aspirin on mean platelet volume in patients with paroxysmal atrial fibrillation. Platelets. 2012 May 30. [Epub ahead of print]. 


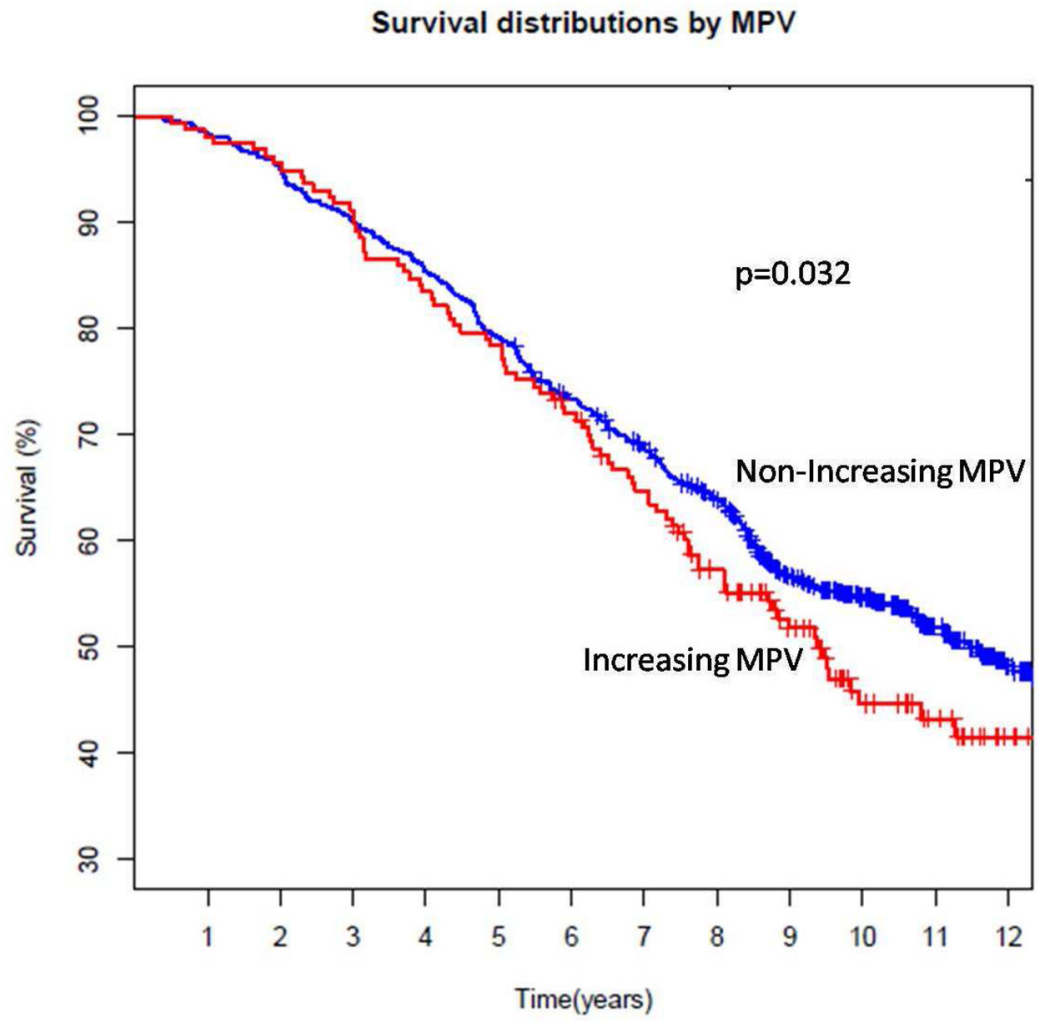

Figure 1.

Association between change in mean platelet volume (MPV) over time and long-term survival 


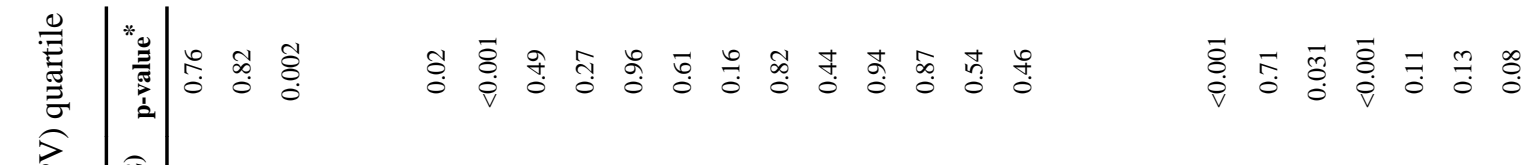

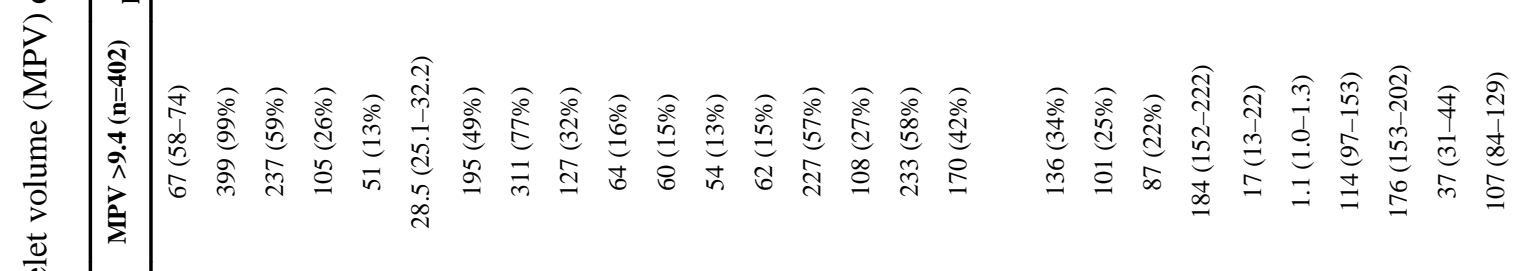

$$
\begin{aligned}
& \text { 䓠 }
\end{aligned}
$$

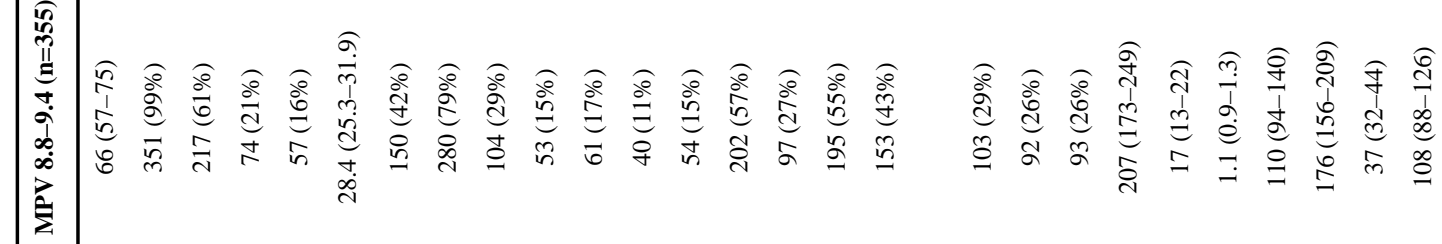

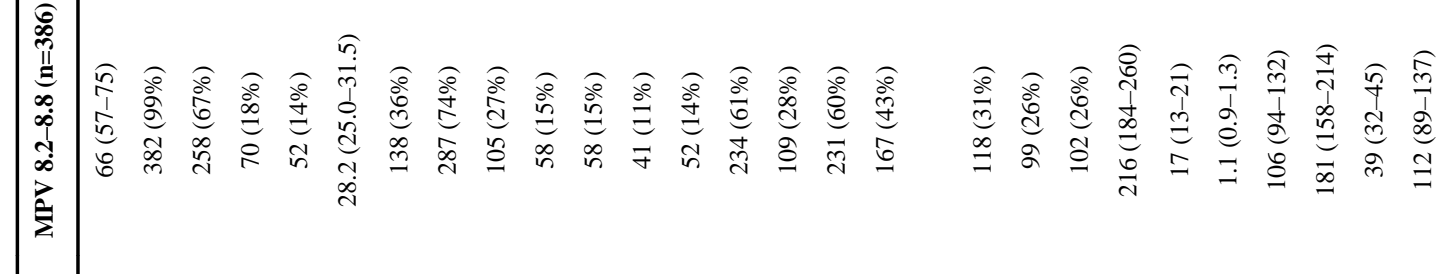




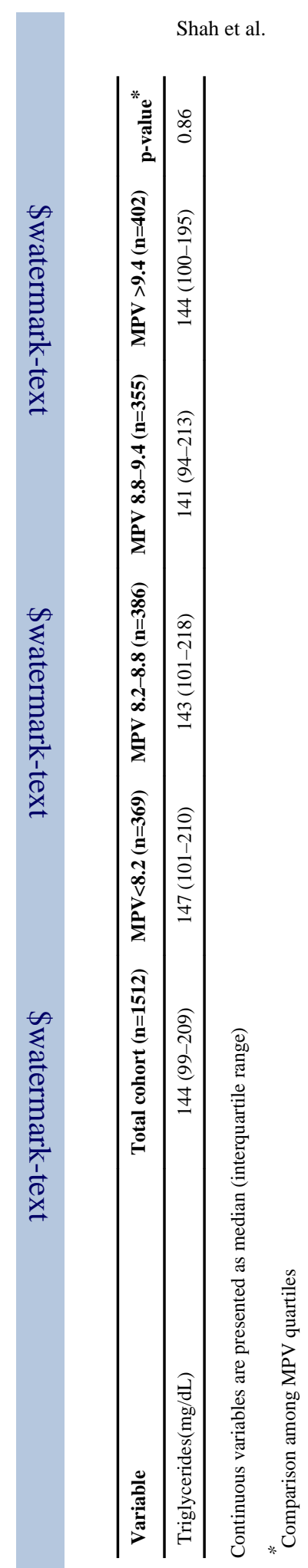

Page 9

Am J Cardiol. Author manuscript; available in PMC 2014 January 15. 
Table 2

Baseline characteristics of cohort undergoing percutaneous coronary intervention (PCI) according to direction of change in mean platelet volume (MPV) over time post-procedure

\begin{tabular}{|c|c|c|c|c|}
\hline Variable & Increasing MPV (n=157) & Decreasing MPV (n=120) & $\underset{(n=562)}{\text { No Change in MPV }}$ & p-value \\
\hline Age (years) & $65(56-75)$ & $68(60-75)$ & $67(658-75)$ & 0.58 \\
\hline Men & $154(98 \%)$ & $120(100 \%)$ & $556(99 \%)$ & 0.31 \\
\hline White & $100(64 \%)$ & $69(58 \%)$ & $384(68 \%)$ & 0.24 \\
\hline Black & $33(21 \%)$ & $33(28 \%)$ & $107(19 \%)$ & \\
\hline Hispanic & $22(14 \%)$ & $15(13 \%)$ & $60(11 \%)$ & \\
\hline Body mass index $\left(\mathrm{kg} / \mathrm{m}^{2}\right)$ & $28.2(25.4-31.9)$ & $28.2(25.4-31.9)$ & $28.1(24.9-32.2)$ & 0.90 \\
\hline Diabetes mellitus & $65(41 \%)$ & $48(40 \%)$ & $244(43 \%)$ & 0.75 \\
\hline Hypertension & $119(76 \%)$ & $100(83 \%)$ & $444(79 \%)$ & 0.31 \\
\hline Prior myocardial infarction & $52(33 \%)$ & $29(24 \%)$ & $172(31 \%)$ & 0.38 \\
\hline Prior coronary artery bypass surgery & $27(17 \%)$ & $13(11 \%)$ & $100(18 \%)$ & 0.19 \\
\hline Prior PCI & $27(17 \%)$ & $13(11 \%)$ & $95(17 \%)$ & 0.27 \\
\hline Heart failure & $15(10 \%)$ & $14(12 \%)$ & $73(13 \%)$ & 0.46 \\
\hline Peripheral vascular disease & $40(26 \%)$ & $18(15 \%)$ & $77(14 \%)$ & 0.003 \\
\hline Hyperlipidemia & $96(61 \%)$ & $65(64 \%)$ & $332(59 \%)$ & 0.38 \\
\hline Current smoker & $41(26 \%)$ & $33(28 \%)$ & $134(24 \%)$ & 0.59 \\
\hline Prior aspirin use & $82(52 \%)$ & $71(59 \%)$ & $307(55 \%)$ & 0.14 \\
\hline Prior statin use & $68(43 \%)$ & $48(40 \%)$ & $246(44 \%)$ & 0.59 \\
\hline Number of vessels narrowed & & & & 0.17 \\
\hline 1 & $51(33 \%)$ & $29(24 \%)$ & $166(30 \%)$ & \\
\hline 2 & $39(25 \%)$ & $41(34 \%)$ & $145(26 \%)$ & \\
\hline 3 & $36(23 \%)$ & $24(20 \%)$ & $149(27 \%)$ & \\
\hline Baseline MPV (fL) & $8.6(8.1-9.4)$ & $8.9(8.2-9.3)$ & $8.8(8.2-9.5)$ & 0.22 \\
\hline Platelet count $\left(\times 10^{9} / \mathrm{L}\right)$ & $218(172-279)$ & $204(173-243)$ & $203(166-253)$ & 0.08 \\
\hline Urea (mg/dL) & $17(13-24)$ & $16(13-20)$ & $17(13-22)$ & 0.23 \\
\hline Creatinine (mg/dL) & $1.1(0.9-1.4)$ & $1.0(0.9-1.3)$ & $1.1(1.0-1.3)$ & 0.07 \\
\hline Glucose (mg/dL) & $114(97-137)$ & $110(93-138)$ & $109(95-141)$ & 0.62 \\
\hline Cholesterol (mg/dL) & $178(156-213)$ & $179(151-207)$ & $179(154-207)$ & 0.94 \\
\hline $\begin{array}{l}\text { High density lipoprotein-cholesterol (mg/ } \\
\text { dL) }\end{array}$ & $37(32-44)$ & $38(32-44)$ & $37(32-44)$ & 0.98 \\
\hline $\begin{array}{l}\text { Lowdensity lipoprotein - cholesterol (mg/ } \\
\text { dL) }\end{array}$ & $108(83-135)$ & $110(80-132)$ & $109(87-132)$ & 0.90 \\
\hline Triglycerides(mg/dL) & $142(93-211)$ & $140(97-197)$ & $145(101-213)$ & 0.78 \\
\hline
\end{tabular}

Continuous variables are presented as median (interquartile range) 


\section{Table 3}

Association between increase in mean platelet volume (MPV) over time and long-term mortality (total cohort of 839 patients (a); 111 patients when using a more stringent definition of increasing MPV (b)

\begin{tabular}{lccc}
\hline Model* $^{*}$ & Odds Ratio & $\mathbf{9 5 \%}$ CI & p-value \\
\hline Unadjusted & 1.34 & $(0.95,1.90)$ & 0.099 \\
Adjusted for age & 1.47 & $(1.06,2.14)$ & 0.039 \\
Adjusted for age and race & 1.48 & $(1.02,2.15)$ & 0.038 \\
Adjusted for age, race, and diabetes & 1.37 & $(0.86,1.88)$ & 0.200 \\
Adjusted for age, race, diabetes and peripheral vascular disease & 1.36 & $(0.81,1.94)$ & 0.206 \\
Adjusted for age, race, diabetes, peripheral vascular disease, creatinine and smoking & 1.40 & $(0.83,1.99)$ & 0.188 \\
\hline & & & \\
\hline Model & Odds Ratio & $\mathbf{9 5 \%}$ CI & p-value \\
\hline Unadjusted & 2.8 & $(1.31,6.43)$ & 0.009 \\
Adjusted for age & 2.73 & $(1.22,6.29)$ & 0.016 \\
Adjusted for age and race & 2.89 & $(1.27,6.72)$ & 0.012 \\
Adjusted for age, race, and diabetes & 2.80 & $(1.23,6.62)$ & 0.016 \\
Adjusted for age, race, diabetes and peripheral vascular disease & 2.61 & $(1.13,6.22)$ & 0.026 \\
Adjusted for age, race, diabetes, peripheral vascular disease, creatinine and smoking & 1.82 & $(0.74,4.57)$ & 0.189 \\
\hline CI=confidence interval & & &
\end{tabular}

